\section{Introdução à Chamada de Artigos Tutoriais de Pesquisa Qualitativa em Estudos de Administração Contemporânea para Edição Especial da RAC: Um Editorial}

Introduction to the Special Issue Call for Qualitative Research Tutorials in Contemporary Administration Studies: An Editorial
Evelyn Lanka*1 Ali Rostron ${ }^{2} \bullet$ Pallavi Singh ${ }^{3 \oplus}$ Sanjay Lanka ${ }^{4}$

\section{INTRODUÇÃO}

No editorial da nossa edição especial, esboçamos uma perspectiva da pesquisa qualitativa e a necessidade de abordar o ensino de métodos qualitativos para ajudar a promover sua aplicação mais rigorosa em estudos contemporâneos de administração e gestão (Lanka, Lanka, Rostron, \& Singh, 2021). Nesse sentido, a chamada de artigos tutoriais para publicação na RAC - Revista de Administração Contemporânea (Lanka, Lanka, Rostron, \& Singh, 2019) foi o mecanismo pelo qual buscamos promover a conscientização, a compreensão e o aprendizado de como pesquisadores em administração e gestão podem aplicar os métodos de pesquisa qualitativa de maneira adequada e eficaz. Esse editorial visa posicionar a edição especial da RAC e apresentar nossas reflexóes sobre temas importantes e urgentes relacionadas à pesquisa qualitativa, temas que são fundamentais para o futuro desse tipo de pesquisa em nosso campo. Apresentaremos também os trabalhos aceitos na chamada de artigos tutoriais para essa ediçáo especial e mostraremos como cada um contribui para a compreensão dos métodos de pesquisa qualitativa.

\footnotetext{
* Autora Correspondente.
}

1. Cranfield University, Cranfield School of Management, Cranfield, Reino Unido.

2. University of Liverpool, Liverpool, Reino Unido.

3. Sheffield Hallam University, Sheffield, Reino Unido.

4. Fundação Getulio Vargas, Escola de Administração de Empresas de São Paulo, São Paulo, SP, Brasil.

\section{QUESTÕES CHAVE EM MÉTODOS DE PESQUISA QUALITATIVA EM ESTUDOS DE GESTÃO}

\section{Os desafios da generalização, validade e confiabilidade na pesquisa qualitativa}

Para aqueles que mudam seu foco analítico da pesquisa quantitativa para a qualitativa, muitas vezes surge a questáo de como avaliar o rigor dessa última. Muitos pesquisadores novatos podem se sentir pressionados a provar que seus resultados de pesquisa qualitativa são 'válidos' ou representam uma 'realidade verdadeira' (Hamilton, 2020). Essa questão traz um desafio significativo para a pesquisa qualitativa. Na perspectiva de seus críticos - aqueles que adotam a pesquisa nomotética (ou quantitativa) - a pesquisa qualitativa é inválida já que não é capaz de oferecer generalizaçóes (Maxwell, 2021). Certamente muitos estudiosos que usam métodos qualitativos argumentariam que não há necessidade de avaliar esse tipo de pesquisa a partir de padróes quantitativos. Esse argumento é baseado

Como citar: Lanka, E., Rostron, A., Singh, P., \& Lanka, S. (2022). Introdução à chamada de artigos tutoriais de pesquisa qualitativa em estudos de administração contemporânea para edição especial da RAC: Um editorial. Revista de Administração Contemporânea, 26(4), e210333. https://doi.org/10.1590/1982-7849rac2022210333.por 
na compreensão das diferenças entre os fundamentos ontológicos e epistemológicos dos métodos de pesquisa.

No entanto, ainda é verdade que a capacidade de generalização de uma pesquisa é muitas vezes tida como uma marca de seu rigor, e essa perspectiva, é claro, se baseia na premissa de que há apenas uma realidade mensurável e objetiva (Hamilton, 2020). Assim, se algo é considerado verdadeiro em uma situação, deve ser verdadeiro em todas as outras, pois elas são igualmente representativas da única realidade definível. No entanto, muitas vezes náo fica claramente compreensível o que significa generalizar, ou generalização (Maxwell, 2021). A falta de definiçôes precisas e claras de como a generalizaçáo pode ser avaliada e se ela se aplica apenas à nomotética, ou também se pode aplicar à pesquisa ideográfica (qualitativa), é um elemento que precisa ser considerado.

Nesse sentido, Firestone (1993) oferece alguns insights promissores. Ele propôs que existem três formas de generalização com as quais os pesquisadores deveriam se preocupar. São elas: (a) extrapolação da amostra para a populaçáo; (b) generalização analítica ou extrapolação usando uma teoria; e (c) traduçáo caso a caso (conforme citado por Varpio et al., 2021). O primeiro exemplo de generalização, (a), refere-se à generalização estatística, onde os resultados são derivados de uma grande amostra considerada estatisticamente representativa e são, portanto, considerados estatisticamente aplicáveis a toda a população. Essa é a forma de generalização mais frequente e é com base nela - provavelmente devido à falta de compreensáo de outras formas - que os pesquisadores quantitativos tentam avaliar a pesquisa qualitativa. No entanto, é crucial que fique claro que, do ponto de vista ontológico da pesquisa qualitativa, generalizar a partir das estatísticas não é necessário nem desejável.

O segundo argumento, (b), é generalizabilidade analítica ou teórica, conforme descrito por Varpio et al. (2021). Nessa perspectiva, o pesquisador visa avaliar descobertas locais por meio do desenvolvimento de novas teorias ou validação de teorias existentes. Segundo Varpio et al. (2021):

"nessa abordagem degeneralização, os pesquisadores se envolvem em análises indutivas e profundas de dados para gerar abstraçóes de ordem superior relevantes para muitos de seus participantes de pesquisa. Essas teorias ou conceitos desenvolvidos pelo esforço de pesquisa são os resultados generalizáveis" (Varpio et al., 2021, p. 170, traduçáo nossa).

De maneira crítica, embora essa forma de generalização seja a mais relevante para pesquisadores qualitativos, eles raramente usam essa linguagem, talvez por receio de serem acusados de querer agradar os pesquisadores quantitativos. Essa visáo de generalizaçáo conceitual ou teórica está profundamente fundamentada no conceito de validade ecológica, que se refere à validação dos resultados de uma pesquisa em relaçáo ao contexto a partir do qual foram coletados (Schmuckler, 2001), ou seja, o quão próximo as descobertas representam e trazem à luz a experiência vivida pelos participantes da pesquisa.

Firestone (1993) também descreve uma terceira abordagem, (c), como generalizabilidade naturalística. A partir dessa abordagem, o pesquisador se preocupa em compreender ou descrever como uma pessoa em um ambiente considera adotar um programa ou ideia de outro. Isso é semelhante ao conceito de transferibilidade de Guba e Lincoln (1989). Tanto Firestone (1993) quanto Varpio et al. (2021) esboçam que, pesquisadores qualitativos aqueles que tratam sua pesquisa a partir de uma abordagem construcionista social e/ou indutiva - podem ter como objetivo a generalização teórica (abordagem b) e/ou a naturalística (abordagem c), se escolherem envolver-se com o conceito de generalização.

No entanto, abordar a generalização não é a única questấo urgente para os pesquisadores qualitativos (Hamilton, 2020). Existe a preocupação contínua de abordar e controlar o viés do pesquisador e garantir a confiabilidade e a validade da pesquisa qualitativa (Guba \& Lincoln, 1989; Kirk \& Miller, 1986; Maxwell, 1992). Embora seja claramente necessário avaliar as pesquisas e garantir que não entrem no discurso as que sejam claramente tendenciosas, motivadas por racismo, sexismo e assim por diante, presumir que os métodos qualitativos são mais suscetíveis a essas questôes em comparação aos métodos de pesquisa quantitativos é uma visão míope (Golafshani, 2003). É importante compreender que tanto a pesquisa qualitativa quanto a quantitativa podem ser influenciadas pelo viés do pesquisador, em como e quais dados são coletados, como são interpretados e como e onde são disseminados.

Em lugar de tentar controlar todos os vieses, pode ser mais útil reconhecer sua existência inevitável e nosso papel como pesquisadores que náo são livres de apresentar tendência, observando como isso pode afetar nossa pesquisa (Golafshani, 2003; Maxwell, 1992; Maxwell, 2021). Muitos pesquisadores qualitativos incorporam em suas práticas de pesquisa meios para reconhecer e refletir sobre o papel do viés no processo. Isso é conhecido como reflexividade e é um meio produtivo pelo qual todos os pesquisadores podem obter maior compreensão de como seu papel na geraçáo de conhecimento pode moldar sua interpretação e dar sentido às histórias contadas a eles pelos participantes da pesquisa (Braun \& Clarke, 2019). Muitos pesquisadores qualitativos que praticam a reflexividade consideram útil manter um diário como parte do processo de análise e coleta de dados. Nessa prática, os pesquisadores documentam suas atividades 
à medida que avançam no trabalho, refletindo, criticando e analisando seus próprios pensamentos, emoções e percepçóes sobre o projeto de pesquisa (Finlay, 2002; Macbeth, 2001; Shaw, 2010; Watt, 2007). No entanto, a reflexividade não é simplesmente um meio pelo qual traçamos linhas em torno de nossas próprias noçôes preconcebidas sobre a pesquisa (Berger, 2015; Bott, 2010; Skeggs, 2002). Mauthner e Doucet (2003) reflexividade também é importante ao pesquisar e escrever sobre a vida de outras pessoas, porque força os pesquisadores a serem explícitos sobre seu papel na apresentação de dados que efetivamente vêm da vida e experiências de outros, dando assim espaço para delinearem como e por que eles interpretaram seus dados da maneira que o fizeram. Conforme destacam Braun e Clarke (2019) a subjetividade do pesquisador deve ser vista como um recurso e não como uma fragilidade no processo qualitativo.

Além disso, no que diz respeito à validade e confiabilidade em pesquisas qualitativas, pode ser útil entender o que tem sido proposto sobre a avaliaçáo do quanto a pesquisa qualitativa é digna de crédito. Guba (1981) e Guba e Lincoln (1989) afirmam que existem quatro principais preocupaçóes para avaliar a confiabilidade dos dados qualitativos. São elas: valor de verdade, aplicabilidade, consistência e neutralidade (Guba, 1981). O valor de verdade é o conceito de como se pode estabelecer confiança na verdade das descobertas qualitativas (Guba, 1981). A aplicabilidade diz respeito ao grau em que os resultados podem ser aplicados em outros ambientes ou contextos (Guba, 1981). A consistência versa se os resultados podem ser repetidos de forma consistente no mesmo contexto (Guba, 1981) e, finalmente, a neutralidade trata de como "estabelecer o grau em que os resultados foram gerados pelos participantes do estudo e não pelo pesquisador, como resultado de seus preconceitos, motivações, interesses, perspectivas e assim por diante" (Guba, 1981, p. 80, tradução nossa). Essas diretrizes são fornecidas novamente para pesquisadores que podem precisar se envolver com esses conceitos em seu processo de pesquisa ou para aqueles que podem achar esses conceitos úteis para envolvimento com um público específico. No entanto, muitos pesquisadores qualitativos ainda podem não achar útil ou necessário envolver-se com discursos quantitativos sobre validação e documentação de confiabilidade. Essa posição não deve ser interpretada como falta de rigor acadêmico. Em vez disso, indicamos novamente ao leitor os fundamentos ontológicos e epistemológicos subjacentes à pesquisa qualitativa, que abordam a confiabilidade e a validade de maneira diferente da pesquisa quantitativa. Caso o leitor queira revisar essas questóes, ele pode considerar Lanka, Lanka, Rostron e Singh (2021) úteis para consulta. Nossa motivação para delinear essas diferentes visóes é apresentar os dois lados desse argumento, a fim de envolver diferentes públicos com necessidades e abordagens distintas no que diz respeito a como conduzem pesquisas qualitativas. Nesse sentido, achamos útil abordar a seguir as perguntas que a pesquisa qualitativa nos permite fazer.

\section{Quais as perguntas que a pesquisa qualitativa nos permite fazer?}

$\mathrm{O}$ discurso em torno de quais questóes a pesquisa qualitativa ajuda a descobrir está tipicamente enraizado na definição e nos conceitos fundamentais da investigação qualitativa Denzin e Lincoln (2011) definem:

"A pesquisa qualitativa é uma atividade situada que posiciona o observador no mundo. Isso significa que os pesquisadores qualitativos estudam as coisas em seus ambientes naturais, tentando dar sentido ou interpretar os fenômenos nos termos dos significados que as pessoas fornecem a eles" (Denzin \& Lincoln, 2011, p. 3, tradução nossa).

A base da investigação qualitativa visa abordar o significado que indivíduos ou grupos atribuem a um problema social ou humano (Creswell, 2012) e coloca a interaçáo social e os processos sociais no centro dessa abordagem (Strauss, 1987). Portanto, a questão da pesquisa qualitativa precisa articular o que um pesquisador quer saber sobre as intençóes e perspectivas dos envolvidos na interação social e colocar em primeiro plano os pontos de vista dos atores do fenômeno. Envolve fazer perguntas sobre como e o porquê das interaçóes humanas e geralmente leva às respostas que descrevem, explicam ou esboçam a história de um processo social.

Diferente dos estudos quantitativos, uma investigação qualitativa não começa com uma hipótese, mas também não pode começar sem um plano (Richards, 2005). Os pesquisadores precisam de algumas perguntas iniciais; mesmo aqueles que usam a teoria fundamentada começam com questóes mais amplas após entrarem no possível local de pesquisa (Agee, 2009). Boas perguntas podem surgir da curiosidade ou ideias iniciais e podem começar com, por exemplo, 'o que eu quero saber no estudo?' (Janesick, 2000). Charmaz (2006) sugere que questóes amplas como 'o que está acontecendo aqui?', 'Quais são os processos sociais básicos?' e 'quais são os processos psicológicos sociais básicos?', podem servir para ajudar um pesquisador a encontrar algum foco inicial. Marshall e Rossman (2014) descrevem questóes que desempenham quatro funçôes diferentes: exploratória, explicativa, descritiva e emancipatória. Maxwell (2012) chamou essas questóes iniciais de 'provisórias' porque, ao contrário da investigaçáo quantitativa, as questóes da pesquisa qualitativa não estão estagnadas e confirmadas no início do projeto de pesquisa. As questóes mudam durante o processo para refletir uma maior compreensão do problema e seguem 'evoluindo' (Creswell, 2007). 
O desenvolvimento de perguntas qualitativas é um processo contínuo e geralmente é desenvolvido ou refinado em todas as fases do projeto. Agee (2009) chama o desenvolvimento de questóes de pesquisa qualitativa de 'uma jornada de investigação reflexiva e interativa'. As primeiras iterações de perguntas são provisórias e exploratórias, mas oferecem aos pesquisadores uma ferramenta para articular o foco principal do estudo. As perguntas qualitativas devem levar a um processo de exploraçáo e descoberta e não ficarem presas aos motivos que justificaram o 'foco' escolhido e que foram estabelecidos nos estágios iniciais. Começar com perguntas excessivamente focadas pode levar à visão de túnel e pode inibir a compreensáo e análise de um pesquisador (Maxwell, 2012). A criaçáo de perguntas orientadas para a descoberta pode ajudar um pesquisador a usar o processo de desenvolver e refinar perguntas como base para uma investigação mais rigorosa e reflexiva (Agee, 2009). O processo iterativo de desenvolvimento de questóes de pesquisa qualitativa depende da capacidade dos pesquisadores de examinar seu próprio papel e perspectiva, e também como eles se posicionam em relaçáo aos participantes. Portanto, a investigaçáo qualitativa tem mudado gradualmente no sentido de envolver os participantes no processo de desenvolvimento da questão (Flick, 2018; Maxwell, 2012), especialmente na pesquisa-ação participativa, que requer que todos os interessados cujas vidas são afetadas pelo problema em estudo sejam engajados no processo de investigação (Stringer, 2007).

Os estudos qualitativos podem revelar como as pessoas vivenciam e pensam sobre eventos e relaçóes sociais (Flick, 2018). O pesquisador está representando a vida de indivíduos, e os tipos de perguntas que um pesquisador faz tornam-se primordiais quando se considera os efeitos de curto e longo prazo sobre os outros. O desenvolvimento de questóes de pesquisa qualitativa deve incluir um pensamento cuidadoso sobre como a direção da investigação irá posicionar o pesquisador em relaçáo aos participantes e quais serão as implicaçóes para as vidas deles. Esse aspecto ético deve ser parte integrante da conceituação e um processo reflexivo contínuo no desenvolvimento da questáo da pesquisa qualitativa.

\section{Abordando diversas vozes na pesquisa qualitativa}

Além das questóes elaboradas por meio da pesquisa qualitativa, também há a necessidade de compreender como os participantes da pesquisa são considerados e engajados. É reconhecida a necessidade de abordar o espectro de vozes e experiências de indivíduos por meio da pesquisa qualitativa. A pesquisa na administraçáo contemporânea não está imune a essa necessidade e, de fato, tem se esforçado para refletir a diversidade de perspectivas tanto na pesquisa como na formação. Nesse sentido, acreditamos que abordar a pesquisa emancipatória e decolonial é uma forma de dar conta da diversidade de perspectivas na pesquisa qualitativa. Essa abordagem não pede simplesmente aos pesquisadores qualitativos que capturem mais profundamente os tópicos de pesquisa ou participantes, mas os estimula a abordar desafios críticos que silenciaram ou obscureceram certas vozes.

Nesse contexto, gostaríamos de chamar a atenção para a necessidade de usar a pesquisa qualitativa para trazer à tona a perspectiva do subalterno, que definimos como um membro da sociedade cuja perspectiva não só foi reprimida, mas cujas necessidades foram ignoradas tanto pela comunidade empresarial quanto pelos que estáo no poder político. Portanto, estamos em busca de pesquisas qualitativas que questionem o foco nas perspectivas das elites, corporaçóes e sua gestão. A mudança emancipatória real exigirá que aqueles cujas vidas são afetadas pelas açóes do nexo corporativo-estado tenham voz. $\mathrm{Na}$ mesma linha de Cooper e Sherer (1984), essa chamada de trabalhos procura pesquisas nos campos da administração, contabilidade e finanças que "... envolvam uma visão mais emancipada da motivação humana ... uma visão que reconheça o potencial das pessoas (e da contabilidade) para mudar e refletir interesses e preocupaçóes diferentes" (Cooper \& Sherer, 1984, p. 219, tradução nossa). Assim, a ideia é atrair um tipo de pesquisa que chama a atenção para as políticas de governo e as estruturas de governança corporativa que perpetuam "a pobreza, a desigualdade social e a distribuição desigual da riqueza" (Sikka, Wearing, \& Nayak, 1999, p. 5, tradução nossa). Propomos uma mudança fundamental na forma como os acadêmicos se envolvem com a comunidade em geral, assumindo uma postura mais crítica e questionadora, tornando-a mais acessível e deixando claro o papel desempenhado pelas forças históricas e políticas (Willmott, Puxty, \& Sikka, 1993) na perpetuação das desigualdades.

Vemos a necessidade de um maior foco na pesquisa qualitativa, uma vez que o status quo é perpetuado por uma abordagem quantitativa cuja ontologia e epistemologia falham em fazer a pergunta 'por que' em relação a essas desigualdades. Liderança, contabilidade e finanças são exemplos de áreas da pesquisa em gestão e administração contemporânea que mantiveram um controle firme sobre o uso de métodos quantitativos e prolongaram o status quo. A pesquisa qualitativa em estudos de liderança, por exemplo, permite que os pesquisadores abordem a natureza mais subjetiva e socialmente construída de liderança e seguidores (Lanka, Topakas, \& Patterson, 2020). Desse modo, o objetivo da pesquisa qualitativa deve ser apresentar, dar espaço e defender as histórias daqueles cuja voz foi silenciada.

Isso é especialmente crítico para abordar questôeschave, como os impactos das mudanças climáticas e a pandemia da Covid-19, que aumentaram as desigualdades e 
mostraram a falta de responsabilidade do setor corporativo e do governo. A perda de acesso à educação básica, soberania alimentar e emprego, especialmente para mulheres, traz à tona a necessidade de maior interseccionalidade na pesquisa para compreender e remediar os desafios enfrentados pelo desenvolvimento sustentável. Portanto, é necessário enfatizar a perspectiva do subalterno e questionar muitas das suposiçôes tidas como certas, especialmente no que diz respeito ao sistema alimentar e à agricultura. Lanka, Khadaroo e Böhm (2017) fornecem um relato do subalterno, destacando o papel da biodiversidade e dos serviços ecossistêmicos em garantir a subsistência de uma cooperativa de pequenos agricultores indígenas. Isso traz à tona o fato de que temos sistemas socioecológicos, de modo que, quando consideramos o impacto ambiental, devemos também considerar o impacto social relacionado, especialmente sobre os stakeholders menos poderosos, impactados pelas empresas multinacionais. Isso exigirá uma abordagem qualitativa que dê voz à sua perspectiva.

\section{Pesquisa qualitativa - Um campo vivo e animado}

Cada um dos cinco artigos selecionados para esta edição especial trazem uma contribuição particular e importante, tanto para nosso objetivo de promover o valor da pesquisa qualitativa dentro da administraçáo contemporânea e da pesquisa em gestáo, quanto para orientar na realização eficaz de tais pesquisas. $\mathrm{Na}$ segunda metade deste editorial, resumimos cada um deles, sendo que os cinco artigos também discutem e refletem algumas tendências mais amplas no campo dos métodos de pesquisa qualitativa - item que desejamos destacar. Os três temas que elaboramos a seguir sustentam nossa afirmaçáo de que a pesquisa qualitativa não deve ser abordada ou comparada com os paradigmas e as medidas de qualidade dos métodos quantitativos, mas reconhecida como um campo em si, vivo, animado e inovador.

O primeiro tema refletido pelos artigos é a preocupação com métodos de maior amplitude. Tradicionalmente, a pesquisa qualitativa nos estudos contemporâneos de administraçáo e gestão tem sido dominada pelo método de entrevista (Holstein \& Gubrium, 2011) e, com isso em mente, incluímos um artigo de Cheron, Salvagni e Colomby (2022) que aborda esse método em detalhe. Entrevistas qualitativas podem ser um método bem apropriado. Afinal de contas, se você quer saber o que as pessoas pensam sobre um fenômeno, qual seria a melhor maneira se não perguntar a elas e ouvir o que elas têm a dizer sobre suas experiências e perspectivas sobre tal fenômeno? (Cheron, Salvagni, \& Colomby, 2022; Van Manen, 1997; Watson, 1998). No entanto, Silverman (2006) adverte contra se tomar o método como padrão, e os projetos de pesquisa qualitativa dentro dos estudos de gestão têm refletido cada vez mais uma vontade de aplicar e conceber métodos inovadores com os quais investigar e 'chegar a' fenômenos organizacionais, como a elicitaçấo ou coleta de dados visuais (Bell, Warren, \& Schroeder, 2014) e histórias (Gabriel \& Griffiths, 2004; Riessman, 2008). Os artigos selecionados para a edição especial também refletem essa disposição. Deus, Campos e Rocha (2022) apresentam um novo método de coleta e, em seguida, a análise do fenômeno social recente dos memes como uma forma de obter insights alternativos e originais sobre os discursos culturais. Os artigos de Behling, Lenzi e Rossetto (2022) e Silva, Sauerbronn e Thiollent (2022) exploram como métodos relacionados a interactive qualitative analysis (IQA) (análise qualitativa interativa) e pesquisa-ação participativa (PAP), usados mais comumente em outros campos, podem ser aplicada à gestáo, organização e estudos administrativos; e Melo e Dourado (2022) oferecem uma revisão abrangente que amplia a gama e a natureza dos possíveis métodos qualitativos para investigar fenômenos e interações sociais online.

O segundo tema é a resposta a formas emergentes de vida social e organizacional. Como "uma abordagem emergente, indutiva, interpretativa e naturalista para o estudo de pessoas, casos, fenômenos, situaçóes sociais e processos em seus ambientes naturais, a fim de revelar em termos descritivos os significados que as pessoas atribuem às suas experiências do mundo" (Yilmaz, 2013, p. 312), a pesquisa qualitativa continua sendo uma forma essencial de investigar esses ambientes naturais e, especialmente, à medida que esses ambientes evoluem e mudam. A pesquisa qualitativa, portanto, precisa permanecer alerta para as formas emergentes de vida social e fenômenos e ser capaz de projetar e adaptar métodos para nos permitir 'chegar a' - investigar e refletir adequadamente - tais formas. Essa preocupação em discernir e refletir sobre novas e diferentes formas de vida social também ajuda a esclarecer um importante papel complementar para a pesquisa qualitativa em descobrir, explorar e mapear áreas da vida social que podem então ser examinadas, quantificadas e medidas posteriormente.

Uma dessas áreas trata de como a vida social e as interaçóes sociais estão emergindo e evoluindo na esfera online. Enquanto Deus et al. (2022) examinam uma nova forma particular em detalhes - a dos memes como novos textos culturais, Melo e Dourado (2022) procuram discernir e elaborar a natureza particular das interaçóes sociais online e suas implicaçóes para a concepção de métodos qualitativos apropriados para examiná-las. Outra área é a preocupação com a justiça social e, particularmente, como as vozes e experiências subalternas podem não apenas ser reconhecidas e ouvidas, mas também habilitadas a desafiar as vozes, práticas e epistemologias dominantes. Em seu artigo, Silva et al. (2022) vinculam explicitamente a agenda decolonial 
às práticas de pesquisa em si e a imposição e reproduçáo das hegemonias coloniais por meio de práticas de gestão, contabilidade e pesquisa. Eles argumentam que os 'métodos não extrativos', como a pesquisa-ação participativa, oferecem um meio pelo qual a pesquisa pode incluir os participantes náo apenas como sujeitos ou contribuintes, mas como coconstrutores de conhecimento; tema também destacado por Cheron et al. (2022), que observam como as entrevistas 'reformulam' os participantes no processo de pesquisa de 'meras fontes de informação' para coprodutores de conhecimento com base em um interesse comum no fenômeno em estudo. No entanto Silva et al. (2022) discutem como tais métodos também desafiam os 'pontos cegos' do pesquisador decorrentes de seus próprios interesses ou 'grandes teorias', abordando a experiência dos participantes e produzindo conhecimento que é útil nesse contexto local. Essa preocupação com a experiência local, o conhecimento dos participantes e a crítica ao pesquisador que 'tudo sabe e tudo về também se reflete em Behling et al. (2022). O método de análise qualitativa interativa busca não criar teorias para explicar a experiência do participante, mas descobrir 'teorias em ação' que informam e orientam como um grupo dá sentido a um determinado fenômeno e, portanto, também pode ajudar a desafiar o status quo apoiado por teorias em qualquer área do conhecimento. Da mesma forma, Melo e Dourado (2022) também refletem sobre como a natureza das interaçóes sociais online também pode encorajar formas mais colaborativas de pesquisa. Eles observam, em particular, como a esfera online apoia a democratização das práticas de pesquisa descaracterizando certas fronteiras entre pesquisador e pesquisado, por exemplo, porque os pesquisados agora também são capazes de buscar o perfil online dos pesquisadores e sua pegada de mídia digital e social, e porque ambas as partes se encontram e conversam em um espaço virtual compartilhado.

O terceiro tema diz respeito a como os métodos qualitativos podem gerar novas possibilidades de pesquisa de gestão e organizaçóes. Os cinco artigos náo apenas propóem como os métodos qualitativos podem gerar novos conhecimentos de gestão e organizacionais que nos permitem conhecer e compreender melhor, mas como esses métodos também abrem possíveis novas formas de ver, chegar e pensar sobre a administração contemporânea e a própria gestão; essa é a epistemologia da pesquisa de administração e gestão. Esse tema não é de forma alguma uma característica de toda pesquisa qualitativa, e nem é verdade que a pesquisa quantitativa não é capaz de ser altamente inovadora. Entretanto essa característica da pesquisa qualitativa e sua capacidade de desafiar como podemos conhecer a administração e gestáo contemporâneas, e ainda o que pode haver para sabermos, pode ser vista como um reflexo tanto das dificuldades e desafios de justificar métodos de pesquisa qualitativa e demonstrar sua validade e valor, quanto de sua natureza muitas vezes exploratória.
Nossos artigos selecionados colocam (e tentam responder) uma série de questóes relativas às epistemologias e práticas que sustentam esse tipo de pesquisa. Uma pergunta comum é: como podemos compreender melhor? Todos os artigos estão preocupados, até certo ponto, com a ampliação das perspectivas de qualquer fenômeno gerencial, organizacional ou social: buscando e incluindo vozes subalternas (Melo \& Dourado, 2022; Silva, Sauerbronn, \& Thiollent, 2022) e ideologias marginalizadas (Deus, Campos, \& Rocha, 2022), desenvolvendo diálogos e abordagens colaborativas com os participantes da pesquisa (Cheron et al., 2022; Melo \& Dourado, 2022; Silva et al., 2022), descobrindo e revelando teorias endógenas em uso pelos próprios participantes (Silva et al., 2022), refletindo perspectivas múltiplas e diversas (Deus et al., 2022), ou capturando e rastreando atitudes sociais ao longo do tempo (Deus et al., 2022). Uma segunda questão é o que podemos estudar melhor ou como podemos expandir tópicos de interesse e relevância para os estudos de administração e organização. Silva et al. (2022), por exemplo, argumentam que, ao adotar uma abordagem decolonial, não extrativa e participativa, a pesquisa em contabilidade pode se estender além do 'controle da lucratividade para os acionistas' (Silva et al., 2022) para várias formas de preocupaçôes sociais e demandas, como impacto ambiental, violência de gênero e raça, e direitos humanos. Melo e Dourado (2022) argumentam que o processo de descobrir a melhor forma de pesquisar 'online como uma forma plena de vida humana' também leva ao desenvolvimento de novos insights sobre a natureza plena dessa forma de vida e a conhecer o mundo de várias maneiras que ainda não podem ser previstas.

\section{INTRODUÇÃO À EDIÇÃO ESPECIAL}

\section{Memes como um atalho para a cultura do consumo: Uma abordagem metodológica para ideologias coletivas encobertas}

Esse artigo de Deus et al. (2022) propóe o uso metodológico de memes como um atalho para explorar a cultura de consumo. Os autores argumentam que os memes como textos culturais podem revelar ideologias circulantes coletivas que não podem ser acessadas por meio de entrevistas regulares. Memes são textos culturais que veiculam mensagens fáceis de entender, ganhando força nas redes sociais. Os textos culturais apresentam de forma lúdica o contexto social e as crenças das sociedades. Os autores analisaram os memes circulantes durante a pandemia da Covid-19 sobre consumidores idosos no Brasil para traçar um protocolo metodológico. Seu método de análise era reunir e codificar memes, adotando o modelo de discurso para conduzir pesquisas qualitativas sobre os mesmos como um atalho para os discursos culturais. Eles coletaram memes 
entre março e maio de 2020 usando as mídias sociais e entáo codificaram e analisaram seus dados usando a análise temática. Esse processo de análise iniciou-se com o delineamento de um protocolo de coleta de dados, seguido das diretrizes de análise, ilustradas pelo contexto de consumidores idosos. A análise dos memes como textos culturais contribuiu para a compreensão do comportamento do consumidor por meio do conteúdo cultural atual, revelando ideologias contrastantes que emergem dos consumidores, como sistemas de valores descobertos, circulando ao lado de ideologias institucionais de mídia de massa. O valor desse artigo em sua abordagem aos métodos qualitativos é que permite ao leitor compreender como aplicar a análise temática (um método qualitativo bastante popular) às redes sociais. Assim, acreditamos que este artigo contribui significativamente para o ensino de ambos os métodos, bem como para orientar de que maneira os aplicar produtivamente a um tema desafiador e dinâmico como as mídias sociais.

\section{Pistas para 0 desenvolvimento paradigmático dos métodos de pesquisa qualitativa on-line}

Este artigo de Melo e Dourado (2022) discute como as propriedades idiossincráticas do contexto online podem impulsionar o desenvolvimento de futuros métodos qualitativos. Os autores problematizam como os métodos online foram reduzidos a meras adaptaçóes de técnicas anteriores de coleta de dados e identificam os possíveis ingredientes de novos métodos e técnicas qualitativas. Eles identificam cinco pistas para o desenvolvimento paradigmático dos métodos qualitativos online: (a) as novas socialidades permitidas pelas interaçóes online; (b) os processos online envolvidos na afirmaçáo de identidade e de si mesmo; (c) a crescente dificuldade em distinguir online o que é privado do que é público, e o que significa privacidade neste contexto; (d) o aumento da agência dos participantes na pesquisa qualitativa online; e (e) a crescente indistinção entre fenômenos sociais off-line e online. Os autores argumentam que a partir de pressupostos ontológicos e epistemológicos que não consideram as especificidades das experiências online, e por focarmos excessivamente na adaptação de métodos conhecidos às novas configuraçóes, somos obrigados a conceber a experiência online usando categorias off-line, perdendo a oportunidade de desenvolver métodos nativos, paradigmáticos e qualitativos. Acreditamos que esse artigo dá uma contribuição significativa para o apelo desta edição especial, promovendo uma nova forma de abordar como os pesquisadores conduzem pesquisas online. Ele ajuda a reformular a interface online/off-line, fornecendo orientação aos pesquisadores sobre como melhor envolver-se com os métodos online.
Novos problemas, novos métodos: Uso da Interactive Qualitative Analysis (IQA) na pesquisa em Administração

O artigo de Behling et al. (2022) envolve um método relativamente novo conhecido como Interactive Qualitative Analysis (IQA) ou (Análise Qualitativa Interativa). Segundo os autores, esse método é uma estratégia qualitativa a ser utilizada na pesquisa de administração. O IQA visa a construção de um mapa mental compartilhado dos membros do grupo focal sobre o fenômeno em estudo. As etapas de coleta e análise dos dados sáo realizadas paralelamente, sendo que a primeira análise é executada pelos próprios participantes da pesquisa. Os resultados sáo apresentados em um conjunto de relaçóes entre os elementos do mapa mental compartilhado. O caráter indutivo das etapas iniciais, aliado a procedimentos dedutivos, permite descobrir novas formas de pensar os problemas investigados, reforçando o caráter exploratório da pesquisa qualitativa. O protocolo de coleta e análise de dados replicáveis promove confiabilidade e validade no processo de pesquisa ao apresentar evidências empíricas. $O$ valor que o IQA traz para a pesquisa qualitativa é a reformulação da maneira como ela é conduzida, passando de uma abordagem de cima para baixo (liderada pelo pesquisador) para uma abordagem de baixo para cima (liderada pelo participante). Essa abordagem capacita os participantes a conduzir a agenda de pesquisa e dá a eles uma participação maior no processo e na geração de conhecimento. Consideramos que esse envolvimento com os participantes é uma contribuição significativa e necessária para a pesquisa qualitativa - que pode complementar e paralelizar outros métodos existentes, como a pesquisa-açáo participativa (PAP).

\section{Estudos decoloniais, métodos não- extrativistas e pesquisa-ação participativa em Contabilidade}

Esse artigo de Silva et al. (2022) discute como a contabilidade apoia o capitalismo financeiro no Sul Global por meio de linguagens e práticas neocolonialistas, com o objetivo de propor uma agenda decolonial baseada em metodologias náo-extrativistas para recuperar conhecimentos alternativos e (re)construir novos. Os autores delineiam a literatura contábil crítica, conectando-a à epistemologia decolonial. Eles descrevem os pressupostos por trás de diferentes métodos não-extrativistas e contrastam a pesquisa-ação participativa (PAP) com diferentes abordagens para a produção e consumo de conhecimento. Silva et al. (2022) se envolvem na PAP para analisar seus dados no contexto dos estudos de administração e contabilidade e examinam o potencial do método para elaborar uma agenda de contabilidade participativa. Segundo os autores, os métodos náo-extrativistas podem respeitar e valorizar diferentes visóes de mundo em cada fenômeno social. 
Isso aponta para alternativas de pesquisa náo tradicionais $\mathrm{e}$ emancipatórias na produção de um novo 'sentipensante' em contabilidade para decolonizar conhecimentos, corpos e mentes. O artigo apresenta a PAP como permitindo a (re) existência de diferentes visões de mundo, reconhecendo sua capacidade de recuperar e reconstruir o conhecimento 'com' os participantes. A PAP apoia o envolvimento programático com vozes subalternizadas para coproduzir a pluriversalidade na contabilidade - em vez de reproduzir universalismos e fortalece acadêmicos e profissionais para transcender a modernidade ocidental. Consideramos que o artigo oferece significativa contribuição à discussão, dada a nossa visão da pesquisa decolonial e emancipatória como uma ferramenta vital para abordar algumas das deficiências em pesquisa.

\section{A entrevista de abordagem qualitativa em Administração: Um guia para pesquisadores}

Em nosso último artigo, Cheron et al. (2022), nos levam de volta ao que ainda é amplamente considerado como o principal método de pesquisa qualitativa em estudos de organização e gestão: a entrevista qualitativa. $\mathrm{O}$ artigo se posiciona deliberadamente como um 'tutorial', oferecendo um guia passo a passo para considerar se, quando e como usar entrevistas qualitativas, bem como seu design e aplicação. No entanto, também destaca e elabora a intersubjetividade das entrevistas e como isso informa a tomada de decisão necessária na utilizaçáo do método, como tipos de entrevista, preparação e condução da entrevista, variedade de tipos de perguntas possíveis e implicaçóes na análise dos dados coletados. $\mathrm{O}$ artigo também aborda questóes como assimetria e preconceito, e o que oferece validade e confiabilidade dentro de um paradigma qualitativo e intersubjetivo: o que é necessário não são mecanismos para eliminar ou controlar os preconceitos inerentes às relaçóes entre os sujeitos, mas o fundamento de uma teoria da vida cotidiana que considera a intersubjetividade. Os sujeitos - entrevistador e entrevistado - tecem a entrevista juntos, em um encontro social que transcende a mera transferência de informaçóes (Cheron et al., 2022). O artigo, portanto, contribui para a edição especial não apenas por oferecer um guia para pesquisadores novos em entrevistas qualitativas, mas por reafirmar as reivindicaçóes da pesquisa qualitativa para que seja devidamente considerada em seus próprios termos epistemológicos e sua preocupação humanística, que reflete e valoriza adequadamente as experiências, vozes e contribuiçóes únicas daqueles realmente envolvidos nos fenômenos que buscamos investigar.

\section{CONSIDERAÇÕES FINAIS}

O objetivo da edição especial sobre métodos de pesquisa qualitativa é ajudar a lançar novos artigos com foco em metodologias qualitativas na RAC. Este editorial delineando a edição especial também serve para expressar nossas reflexóes sobre várias questóes-chave que representam desafios atuais na realização de pesquisas em estudos de administraçáo contemporânea. Esperamos ter criado um espaço de envolvimento com essas questóes prementes entre os estudos de administraçáo no que diz respeito aos métodos e metodologias qualitativas. Aqui especificamente, esboçamos nossos pensamentos sobre generalização, confiabilidade e validade da pesquisa qualitativa, bem como discutimos os tipos de questão tratadas por essas pesquisas, os desafios de abordar as diversas vozes e o aporte para a pesquisa qualitativa que cada um dos artigos selecionados para essa edição especial oferece. Acreditamos que essas questóes são críticas para o futuro da pesquisa qualitativa e esperamos que esse editorial sirva como uma chamada à ação para questionar as suposiçóes tidas como certas na pesquisa de administração contemporânea.

\section{REFERÊNCIAS}

Agee, J. (2009). Developing qualitative research questions: A reflective process. International Journal of Qualitative Studies in Education, 22(4), 431-447. https://doi.org/10.1080/09518390902736512

Behling, G., Lenzi, F. C., \& Rossetto, C. R. (2022). Upcoming issues, new methods: Using interactive qualitative analysis (IQA) in management research. Revista de Administração Contemporânea, 26(4), e200417. https://doi.org/10.1590/1982-7849rac2022200417.en

Bell, E., Warren, S., \& Schroeder, J. (2014). The visual organization. In: E. Bell, S. Warren \& J. E. Schroeder (Eds.), The Routledge companion to visual organization (pp. 1-16). London: Routledge.
Berger, R. (2015). Now I see it, now I don't: Researcher's position and reflexivityinqualitative research.QualitativeResearch, 15(2), 219-234. https://doi.org/10.1177/1468794112468475

Bott, E. (2010). Favourites and others: Reflexivity and the shaping of subjectivities and data in qualitative research. Qualitative Research, 10(2), 159-173. https://doi.org/10.1177/1468794109356736

Braun, V., \& Clarke, V. (2019). Reflecting on reflexive thematic analysis. Qualitative Research in Sport, Exercise and Health, 11(4), 589-597. https://doi.org/10.1080/2159676X.2019.1628806 
Charmaz, K. (2006). Constructing grounded theory: A practical guide through qualitative analysis. Thousand Oaks, CA: Sage.

Cheron, C., Salvagni, J., \& Colomby, R. K. (2022). The qualitative approachinterviewinadministration:Aguidefor researchers. Revista de Administração Contemporânea, 26(4), e210011. https://doi.org/10.1590/1982-7849rac2022210011.en

Cooper,D.J.,\&Sherer,M.J.(1984). Thevalueofcorporateaccounting reports: Arguments for a political economy of accounting. Accounting, Organizations and Society, 9(3-4), 207-232. https://doi.org/10.1016/0361-3682(84)90008-4

Creswell, J. (2007). Qualitative inquiry and research design: Choosing among five approaches (2 ed.). Thousand Oaks, CA: Sage.

Creswell, J. W. (2012). Qualitative inquiry and research design: Choosing among five approaches (3 ed.). Thousand Oaks, CA: Sage.

Denzin, N. K., \& Lincoln, Y. S. (2011). The Sage handbook of qualitative research. London: Sage.

Deus, E. P. de., Campos, R. D., \& Rocha. A. R. (2022). Memes as shortcut to consumer culture: A methodological approach undercovered collective ideologies. Revista de Administraçâo Contemporânea, 26(4), e210005. https://doi.org/10.1590/1982-7849rac2022210005.en

Finlay, L. (2002). Negotiating the swamp: The opportunity and challenge of reflexivity in research practice. Qualitative Research, 2(2), 209-230. https://doi.org/10.1177/146879410200200205

Firestone, W. A. (1993). Alternative arguments for generalizing from data as applied to qualitative research. Educational Researcher, 22(4), 16-23. https://doi.org/10.3102/0013189X022004016

Flick, U. (2018). An introduction to qualitative research. Thousand Oaks, CA: Sage.

Gabriel, Y., \& Griffiths, D. S. (2004). Stories in organizational research. In C. Cassell \& G. Symon (Eds.), Essential guide to qualitative methods in organizational research (pp. 114126). London: Sage.

Golafshani, N. (2003). Understanding reliability and validity in qualitative research. The Qualitative Report, 8(4), 597-606. https://doi.org/10.46743/2160-3715/2003.1870

Guba, E. G. (1981). Criteria for assessing the trustworthiness of naturalistic inquiries. ECTJ Educational Technology Research and Development, 29(2), 75. https://doi.org/10.1007/BF02766777

Guba, E. G., \& Lincoln, Y. S. (1989). Fourth generation evaluation. Thousand Oaks, CA: Sage.

Hamilton, J. B. (2020). Rigor in qualitative methods: An evaluation of strategies among underrepresented rural communities. Qualitative Health Research, 30(2), 196204. https://doi.org/10.1177/1049732319860267

Holstein, J. A., \& Gubrium, J. F. (2011). Animating interview narratives. In D. Silverman (Ed.), Qualitative research: Issues of theory, method and practice (3 ed., pp.149-167). Thousand Oaks, CA: Sage.
Janesick, V. (2000). The choreography of qualitative research design: Minuets, improvisations, and crystallization. In N. K. Denzin \& Y. S. Lincoln (Eds.), Handbook of qualitative research (2 ed., Chap. 13, pp. 379-399). Thousand Oaks, CA: Sage.

Kirk, J., \& Miller, M. L. (1986). Reliability and validity in qualitative research (Vol. 1). Thousand Oaks, CA: Sage. https://doi.org/10.4135/9781412985659

Lanka, S. V., Khadaroo, I., \& Böhm, S. (2017). Agroecology accounting: Biodiversity and sustainable livelihoods from the margins. Accounting, Auditing o Accountability Journal, 30(7), 1592-1613. https://doi.org/10.1108/AAAJ-12-2015-2363

Lanka, E., Lanka, S., Rostron, A., \& Singh, P. (2019). Research methods in qualitative management research. Zenodo. https://doi.org/10.5281/zenodo.3934265

Lanka, E., Lanka, S., Rostron, A., \& Singh, P. (2021). Why we need qualitative research in management studies. Revista de Administração Contemporânea, 25(2), e200297. https://doi.org/10.1590/1982-7849rac2021200297.en

Lanka, E., Topakas, A., \& Patterson, M. (2020). Becoming a leader: Catalysts and barriers to leader identity construction. European Journal of Work and Organizational Psychology, 29(3), 377-390. https://doi.org/10.1080/1359432X.2019.1706488

Macbeth, D. (2001). On "reflexivity" in qualitative research: Two readings, and a third. Qualitative Inquiry, 7(1), 35-68. https://doi.org/10.1177/107780040100700103

Marshall, C., \& Rossman, G. B. (2014). Designing qualitative research. Thousand Oaks, CA: Sage.

Mauthner,N.S., \&Doucet,A.(2003). Reflexiveaccountsandaccounts of reflexivity in qualitative data analysis. Sociology, 37(3), 413-431. https://doi.org/10.1177/00380385030373002

Maxwell, J. (1992). Understanding and validity in qualitative research. Harvard Educational Review, 62(3), 279-301. https://doi.org/10.17763/haer.62.3.8323320856251826

Maxwell, J. A. (2012). Qualitative research design: An interactive approach (3 ed.). Thousand Oaks, CA: Sage.

Maxwell, J. A. (2021). Why qualitative methods are necessary for generalization. Qualitative Psychology, 8(1), 111-118. https://doi.org/10.1037/qup0000173

Melo, N. C. M., \& Dourado, D. C. P. (2022). Clues for the paradigmatic development of online qualitative methods. Revista de Administração Contemporânea, 26(4), e210015. https://doi.org/10.1590/1982-7849rac2022210015.en

Richards, L. (2005). Handling qualitative data: A practical guide. Thousand Oaks, CA: Sage.

Riessman, C. K. (2008). Narrative methods for the human sciences. Thousand Oaks, CA: Sage.

Schmuckler, M. A. (2001). What is ecological validity? A dimensional analysis. Infancy, 2(4), 419-436. https://doi.org/10.1207/S15327078IN0204 02 
Shaw, R. (2010). Embedding reflexivitywithin experiential qualitative psychology. Qualitative Research in Psychology, 7(3), 233243. https://doi.org/10.1080/14780880802699092

Sikka, P., Wearing, R. T., \& Nayak, A. (1999). No accounting for exploitation. Basildon, England: Association for Accountancy \& Business Affairs.

Silva, C. M., Sauerbronn, F. F., \& Thiollent, M. (2022). Decolonial studies, non-extractive methods, and participatory action research in Accounting. Revista de Administração Contemporânea, 26(4), e210014. https://doi.org/10.1590/1982-7849rac2022210014.en

Silverman, D. (2006). Interpreting qualitative data. London, UK: Sage.

Skeggs, B. (2002). Techniques for telling the reflexive self. In T. May (Ed.), Qualitative research in action (pp. 350-374). Thousand Oaks, CA: Sage.

Strauss, A. L. (1987). Qualitative analysis for social scientists. Cambridge, UK: Cambridge University Press.

Stringer, E. (2007). Action research (3 ed.). Thousand Oaks, CA: Sage.

\section{Autoria}

\section{Evelyn Lanka*}

Cranfield University, Cranfield School of Management

College Rd, Cranfield, Wharley End, Bedford MK43 0AL, United

Kingdom.

E-mail: Lyn.Lanka@cranfield.ac.uk

(1) https://orcid.org/0000-0003-0674-9955

\section{Ali Rostron}

University of Liverpool

Liverpool L69 3BX, United Kingdom

E-mail: a.rostron@liverpool.ac.uk

(1) https://orcid.org/0000-0003-1803-720X

\section{Pallavi Singh}

Sheffield Hallam University

City Campus, Howard Street, Sheffield, S1 1WB, United Kingdom.

E-mail: p.singh@shu.ac.uk

(1) https://orcid.org/0000-0002-1933-5236

\section{Sanjay Lanka}

Fundaçáo Getulio Vargas, Escola de Administração de Empresas de São Paulo

Rua Itapeva, 474, 01332-000, São Paulo, SP, Brazil.

E-mail: sanjay.lanka@fgv.br

(1) https://orcid.org/0000-0003-0045-1971

* Autora Correspondente
Van Manen, M. (1997). Researching lived experience (2 ed.). London, ON, Canada: The Althouse Press.

Varpio, L., O’Brien, B., Rees, C. E., Monrouxe, L., Ajjawi, R., \& Paradis, E. (2021). The applicability of generalisability and bias to health professions education's research. Medical Education, 55(2), 167-173. https://doi.org/10.1111/medu.14348

Watson, T. J. (1998). The labour of division: The manager as 'self' and 'other.' The Sociological Review, 45(1_suppl), 139-154. https://doi.org/10.1111/j.1467-954X.1997.tb03458.x

Watt, D. (2007). On becoming a qualitative researcher: The value of reflexivity. The Qualitative Report, 12(1), 82-101. https://doi.org/10.46743/2160-3715/2007.1645

Willmott, H., Puxty, T., \& Sikka, P. (1993). Losing one's reason: On the integrity of accounting academics. Accounting, Auditing \& Accountability Journal, 6(2). https://doi.org/10.1108/09513579310036404

Yilmaz, K. (2013). Comparison of quantitative and qualitative research traditions: Epistemological, theoretical, and methodological differences. European Journal of Education, 48(2), 311-325. https://doi.org/10.1111/ejed.12014

\section{Conflito de Interesses}

Os autores informaram que não há conflito de interesses.

\section{Direitos Autorais}

A RAC detém os direitos autorais deste conteúdo.

\section{Verificação de Plágio}

A RAC mantém a prática de submeter todos os documentos aprovados para publicaçáa à verificaçáo de plágio, mediante o emprego de ferramentas específicas, e.g.: iThenticate.

\section{CORPO EDITORIAL CIENTÍFICO E EQUIPE EDITORIAL PARA ESTA EDIÇÃO:}

\section{Conselho Editorial}

Alketa Peci (EBAPE/FGV, Rio de Janeiro, RJ, Brasil)

Gabrielle Durepos (Mount Saint Vincent University, Halifax, Nova Scotia, Canadá)

Rafael Alcadipani da Silveira (EAESP/FGV, São Paulo, SP, Brasil)

Rafael Barreiros Porto (UnB, Brasília, DF, Brasil)

Silvia Gherardi (University of Trento, Trento, Itália)

\section{Editor-chefe}

Marcelo de Souza Bispo (UFPB, João Pessoa, PB, Brasil)

\section{Editores Associados}

Ariston Azevedo (UFRGS, Porto Alegre, RS, Brasil) Carolina Andion (UDESC, Florianópolis, SC, Brasil)

Denize Grzybovski (UPF, Passo Fundo, RS, Brasil)

Eduardo da Silva Flores (FEA/USP, São Paulo, SP, Brasil) 
Elisa Yoshie Ichikawa (UEM, Maringá, PR, Brasil)

Emílio José M. Arruda Filho (UNAMA, Belém, PA, Brasil)

Evelyn Lanka (Cranfield School of Management, Bedford, Reino Unido)

Fernando Luiz Emerenciano Viana (Unifor, Fortaleza, CE, Brasil) Gaylord George Candler (University of North Florida, Jacksonville, Florida, EUA)

Gustavo da Silva Motta (UFF, Niterói, RJ, Brasil)

Keysa Manuela Cunha de Mascena (Unifor, Fortaleza, CE, Brasil) Ludmila de Vasconcelos Machado Guimarães (CEFET-MG, Belo Horizonte, MG, Brasil)

Natália Rese (UFPR, Curitiba, PR, Brasil)

Orleans Silva Martins (UFPB, João Pessoa, PB, Brasil)

Pablo Isla Madariaga (Universidad Técnica Federico Santa María, Chile)

Paula Castro Pires de Souza Chimenti (UFRJ/Coppead, Rio de Janeiro, Brasil)

Rafael Chiuzi (University of Toronto Mississauga, Mississauga, ON, Canadá)

Sidnei Vieira Marinho (Univali, São José, SC, Brasil)

\section{Corpo Editorial Científico}

André Luiz Maranhão de Souza-Leão (UFPE, Recife, CE, Brasil)

Aureliano Angel Bressan (CEPEAD/UFMG, Belo Horizonte, MG, Brasil)

Bryan Husted (York University, Canadá)

Carlos M. Rodriguez (Delaware State University, EUA)

Cristiana Cerqueira Leal (Universidade do Minho, Portugal)

Diógenes de Souza Bido (Mackenzie, São Paulo, SP, Brasil)

Erica Piros Kovacs (Kelley School of Business/Indiana University, EUA)

Elin Merethe Oftedal (University of Stavanger, Noruega)

Fábio Frezatti (FEA/USP, São Paulo, SP, Brasil)

Felipe Monteiro (INSEAD Business School, EUA)
Howard J. Rush (University of Brighton, Reino Unido)

James Robert Moon Junior (Georgia Institute of Technology, EUA)

John L. Campbell (University of Georgia, EUA)

José Antônio Puppim de Oliveira (United Nations University, Yokohama, Japão)

Julián Cárdenas (Freie Universität, Berlin, Alemanha)

Lucas A. B. de Campos Barros (FEA/USP, São Paulo, SP, Brasil)

Luciano Rossoni (UniGranRio, Rio de Janeiro, RJ, Brasil)

M. Philippe Protin (Université Grenoble Alpes, França)

Paulo Estevão Cruvinel (Embrapa Instrumentação, São Carlos, SP, Brasil)

Rodrigo Bandeira de Mello (Merrimack College, EUA)

Rodrigo Verdi (MIT Massachusetts Institute of Technology, Cambridge, EUA)

Valter Afonso Vieira (UEM, Maringá, PR, Brasil)

Wagner A. Kamakura (Jones Graduate School of Business, Rice University, Houston, EUA)

\section{Editoração}

Diagramação e normas da APA: Kler Godoy (ANPAD, Maringá, Brasil); Simone L. L. Rafael (ANPAD, Maringá, Brasil).

Periodicidade: Publicação contínua.

Circulação: Acesso totalmente gratuito.

\section{Indexadores, Diretórios e Rankings}

Scielo, Redalyc, DOAJ, Latindex, Cengage/GALE, Econpapers,

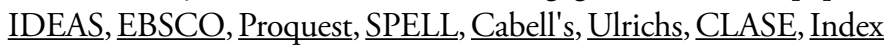
Copernicus International, Sherpa Romeo, Carhus Plus+, Academic Journal Guide (ABS), DIADORIM, REDIB, Sumários.org, ERIHPlus, OAJI, EZB, OasisBR, IBZ Online, WorldWideScience, Google Scholar, Citefactor.org, MIAR, Capes/Qualis. 